\title{
Beyond the cortical column: abundance and physiology of horizontal connections imply a strong role for inputs from the surround
}

Edited by:

Michael Brecht, Humboldt University

Berlin, Germany

Reviewed by:

Dirk Feldmeyer, RWTH Aachen

University, Germany

Gordon M. G. Shepherd, Northwestern

University, USA

Per Jesper Sjöström, University College

London, UK

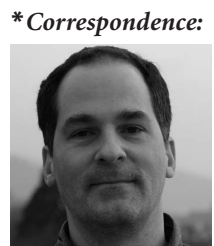

Clemens Boucsein studied biology at the University of Cologne and in the lab of J. Palka in Seattle, working on the light sensitive organs of blow fly larvae. He then joined the group of H. Kettenmann at the MDC Berlin and investigated the electrophysiology of microglia in acute slices. After his Ph.D., he went to the lab of Ad Aertsen in Freiburg, and discovered the fascinating possibilities of combining theoretical and experimental approaches. After 3 years as a post-doc, he became a research group leader and he is now concerned with precision of signal integration and activity propagation in neocortical networks.

clemens.boucsein@biologie.uni-freiburg. de

${ }^{\dagger}$ Clemens Boucsein and Martin P. Nawrot have contributed equally to this work.

\section{Clemens Boucsein ${ }^{1 *+}$, Martin P. Nawrot ${ }^{2+}$, Philipp Schnepel ${ }^{1}$ and Ad Aertsen ${ }^{1}$ \\ 1 Bernstein Center Freiburg, Neurobiology and Biophysics, Faculty of Biology, University of Freiburg, Freiburg, Germany \\ 2 Bernstein Center for Computational Neuroscience and Neuroinformatics and Theoretical Neuroscience, Freie Universität Berlin, Berlin, Germany}

Current concepts of cortical information processing and most cortical network models largely rest on the assumption that well-studied properties of local synaptic connectivity are sufficient to understand the generic properties of cortical networks. This view seems to be justified by the observation that the vertical connectivity within local volumes is strong, whereas horizontally, the connection probability between pairs of neurons drops sharply with distance. Recent neuroanatomical studies, however, have emphasized that a substantial fraction of synapses onto neocortical pyramidal neurons stems from cells outside the local volume. Here, we discuss recent findings on the signal integration from horizontal inputs, showing that they could serve as a substrate for reliable and temporally precise signal propagation. Quantification of connection probabilities and parameters of synaptic physiology as a function of lateral distance indicates that horizontal projections constitute a considerable fraction, if not the majority, of inputs from within the cortical network. Taking these non-local horizontal inputs into account may dramatically change our current view on cortical information processing.

Keywords: reliability, synaptic transmission, dendritic integration, cortical column, temporal coding

\section{TEMPORAL PRECISION AND ITS POSSIBLE ROLE FOR CORTICAL PROCESSING}

Triggered by early theories on coding in neural networks (for an overview, see Perkel and Bullock, 1968), it has been hypothesized that temporal precision of neuronal spiking activity may play an important role for cortical information processing. However, data from early neurophysiological experiments recording responses to stimuli in primary sensory areas suggested that information is contained in the graded elevation of firing rates of cells responding to certain features of the stimulus (e.g., Adrian, 1928; Barlow, 1972). The idea of a rate code henceforth dominated the conceptual thinking about cortical coding and influenced the experimental designs. Experimental evidence supporting more intricate theories based on temporally precise spiking remained, for a long time, relatively rare.

More recently, doubts have been raised whether the above mentioned recordings from strongly responding units are representative for the majority of neocortical cells (Shoham et al., 2006). Both, the refinement of recording techniques and the application of more sophisticated sensory stimuli have provided new insights concerning firing rates and activity dynamics of single neurons in primary sensory areas. Examples include intracellular recordings from anesthetized (Brecht et al., 2003) and awake, behaving mice (Margrie et al., 2002), revealing surprisingly low spike rates in the barrel cortex, even during free exploratory activity. 


\section{Precision}

In temporal coding schemes, this parameter often describes the ability of a neuron to translate synaptic input into precisely timed spike output. Here, we refer to the precision of synaptic transmission, that is, how strong EPSC onset jitters with reference to repeated presynaptic action potentials. This measure relates to temporal coding precision, because precise connections are a pre-requisite for precise output spike timing.

\section{Reliability}

This refers to the reliability of synaptic transmission and describes the probability that a presynaptic AP leads to a faithful transmission at the synaptic terminal, resulting in a postsynaptic current in the target cell.

Experimentally collected values can vary significantly and depend strongly on the pre- and postsynaptic cell-types. Inverse of the failure rate.
When mice changed from quiet wakefulness to active whisking, excitatory cells in that area displayed a clear reduction of firing rates (Crochet and Petersen, 2006) and phase locking to whisker movements (Poulet and Petersen, 2008).

In the auditory cortex, firing rates are particularly low (DeWeese et al., 2003; Hromádka et al., 2008) and decreased even when weak tones were presented against a slowly fluctuating noise background (Las et al., 2005). In fact, neurons in the auditory cortex suppress their spike responses when the animal is engaged in an auditory task (Otazu et al., 2009). In this brain area, neurons have been suggested to operate far away from firing threshold, requiring strongly correlated, transient input for spike generation (DeWeese and Zador, 2006). Functionally, the auditory system seems to be in a position to exploit timing differences as small as $3 \mathrm{~ms}$ between two artificially introduced action potentials for decision making (Yang et al., 2008).

In the visual system, traditionally known for high firing rates during presentation of optimal stimuli, careful considerations of aspects like energy constraints, representation of high numbers of stimulus features, and measurement biases have led to the notion that primary visual cortex may, in fact, use a sparse code (Olshausen and Field, 1996, 2005). A sparse population code had already been implicated earlier in inferotemporal cortex (Young and Yamane, 1992). Support for this view also came from studies showing that responses of single cells become sparser and more reliable when stimulated with natural scenes, especially if the surround of a cell's classical receptive field is included in the stimulation (Vinje and Gallant, 2000; Yen et al., 2006; Haider et al., 2010).

Together, these findings revived the discussion about sparseness of the cortical code and, as a closely related issue, about the possible importance of timing of individual action potentials for information processing (for a review see Wolfe et al., 2010). The concept behind sparse coding is that information is represented with the minimum number of tokens. For populations of spiking neurons, this implies that only very few active neurons code for a specific state, e.g., a particular stimulus configuration (population sparseness), and that each neuron represents information over time with only a small number of spikes per unit time (lifetime sparseness). This, in turn, leads to low firing rates and low noise levels, as were described in the above mentioned experimental studies. In theoretical work, sparse coding has, for instance, been suggested to underlie the processing of complex natural scenes (Field, 1987; Levy and Baxter, 1996; Olshausen and Field,
1996, 2005; Simoncelli, 2003) and in the neural implementation of associative memory (Palm, 1982). Temporal precision of single spikes, on the other hand, is a pre-requisite for concepts like latency coding, with information thought to be contained in differences between timings of action potentials in a population of cells (van Rullen and Thorpe, 2002; Gollisch and Meister, 2008; Jacobs et al., 2009), or theories based on assemblies of synchronized cells (Gerstein et al., 1989; Abeles, 1991; for recent reviews see Harris, 2005; Kumar et al., 2010). Here, precise timing relates to the millisecond or even sub-millisecond range, i.e., a precision in the order of the action potential duration or even higher. It can be argued whether the experimentally observed temporal spike locking to time-varying stimuli in primary sensory areas with a precision that merely reflects the stimulus dynamics should be considered a substrate for temporal coding at all, or whether it might rather be a pre-requisite for it at later processing stages (Aertsen et al., 1979; Harris, 2005; Tiesinga et al., 2008).

Taken together, these considerations have triggered the experimental search for precisely correlated activity of pairs or groups of neurons in higher brain areas. The initially weak evidence was restricted to pairwise correlations (e.g., Aertsen et al., 1989; Vaadia et al., 1995; Alonso et al., 1996), but improved with advances in recording techniques and analysis methods. In particular, a number of studies in awake, behaving monkeys provided strong evidence for a possible relation between spike synchronization and cognitive function (Riehle et al., 1997; Super et al., 2003; Samonds et al., 2004; Maldonado et al., 2008). At the same time, however, it is not clear whether neocortical networks can operate with such precision, also in view of physiological findings on ion channel noise, synaptic variability and non-linear properties of dendritic integration (Häusser et al., 2000; Gulledge et al., 2005). While the necessary steps for precise information transmission in neocortical networks (see Figure 1) have been studied separately, it has not been demonstrated if, and under which conditions, reliable and precise signal propagation in cortical networks is at all possible (Kumar et al., 2010).

\section{HORIZONTAL CORTICAL NETWORKS CAN WORK TEMPORALLY PRECISE AND RELIABLE}

Experimental assessment of the precision and reliability of neocortical network activity is a difficult task. One possible approach is to record membrane potential fluctuations or spiking output of cells in the intact animal, preferably in response to repeated stimulus presentation or in 


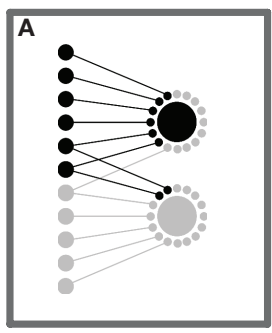

network motif

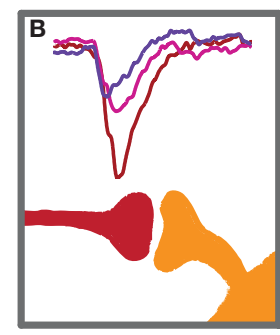

synaptic transmission

FIGURE 1 | Steps of information transmission in neuronal networks. Convergent feed-forward connected neurons (A) are a basic motif for many theories of cortical information processing. A certain degree of convergence is necessary, due to the fact that postsynaptic potentials from single cortical connections are usually too weak to elicit an action potential in the postsynaptic cell. For theories that build on temporally precise signal integration and action potential generation in single neurons, three

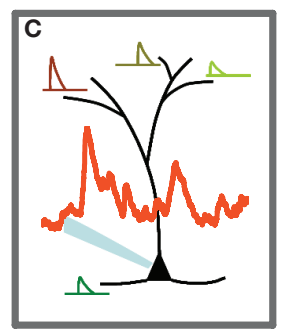

dendritic integration

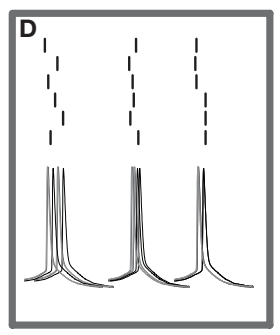

spike generation main steps in activity transfer are critical: synaptic transmission (B), which can show considerable amplitude variability, high failure rates, and temporal jitter (see main text), dendritic integration (C), which has been found to be highly non-linear under certain conditions, and action potential generation (D), the temporal precision of which has been shown to depend on rise time and amplitude of membrane potential deflections, prior to the action potential initiation. relation to identical repetitions of a behavioral task. Even though the above-mentioned studies show that under certain conditions responses can be sparse, highly precise and reliable, others have stressed the high variability, presumably caused by activity unrelated to the stimulus, the so-called ongoing activity (Arieli et al., 1996; Tsodyks, 1999; Ohl et al., 2001; Nawrot, 2010).

A novel experimental approach to precision and reliability in the neocortex, albeit somewhat reduced in terms of complexity of the network involved and regarding the possible sources of variability, was recently established in our lab (Boucsein et al., 2005). This method, dynamic photo stimulation, is especially suited to study reliability and precision of neuronal responses, because it enables tight control of timing and amount of synaptic input to a single cell. Providing repeated, "frozen noise"-type spatiotemporal sequences of synaptic input to a postsynaptic pyramidal neuron in an acute slice, we probed a reduced sub-network of converging excitatory inputs (Figure 1A), which can be considered a basic building block of neocortical networks and models thereof (Abeles, 1991; Diesmann et al., 1999; Kumar et al., 2010). In these experiments, we found that neocortical layer $\mathrm{V}$ pyramidal neurons possess remarkably precise integration capabilities (Figure 2; Nawrot et al., 2009). At first, these results seemed puzzling since a number of previous studies reported unreliable synaptic transmission in the neocortex: Different classes of connections can exhibit high variability in PSP amplitude and high failure rates of up to $70 \%$ (Koester and Johnston, 2005; Bremaud et al., 2007). Other authors reported more reliable synapses with less amplitude variability (Mason et al., 1991; Feldmeyer et al., 1999, 2006; Frick et al., 2008). But even compared with these latter studies, quantification of the physiological properties of synaptic connections probed in our study revealed a strikingly high temporal precision with a temporal jitter of less than $1 \mathrm{~ms}$ (Figure 3C) and close to $100 \%$ reliability in almost all synaptic connections studied (Figure 3A). At the same time, the amplitude variability was moderate (Figure 3B), and accounted for most of the variability observed during postsynaptic signal integration, as shown by a simple model of subthreshold signal integration (Nawrot et al., 2009). Taken together, these findings suggested that synaptic physiology, not action potential propagation or dendritic integration, is the key factor determining amplitude variability and temporal precision in this cortical sub-network of converging excitatory inputs.

What could be the reason for the high precision and reliability observed in this system? Potentially, the method used to find the connections within the acute slice, namely functional mapping with the help of laser-induced glutamate uncaging (Callaway and Katz, 1993; Dodt et al., 2003; Kötter et al., 2005) could have introduced a bias toward exposing especially reliable connections. Performing mapping experiments, covering large areas of the slice, is time consuming, accounting for a low number of trials per location during the phase where putative presynaptic sites are identified (up to four in our experiments; for a discussion, see Boucsein et al., 2005). Thus, unreliable connections might be overlooked. Another striking and important difference to earlier studies on the physiology of synaptic connections is that in 


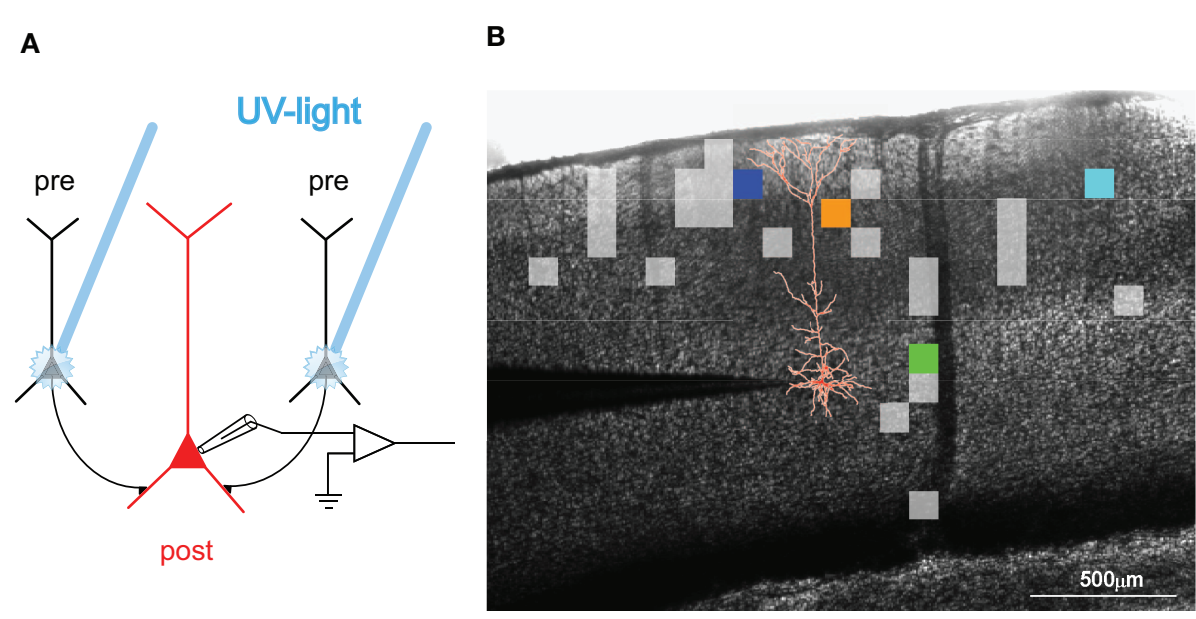

C

D

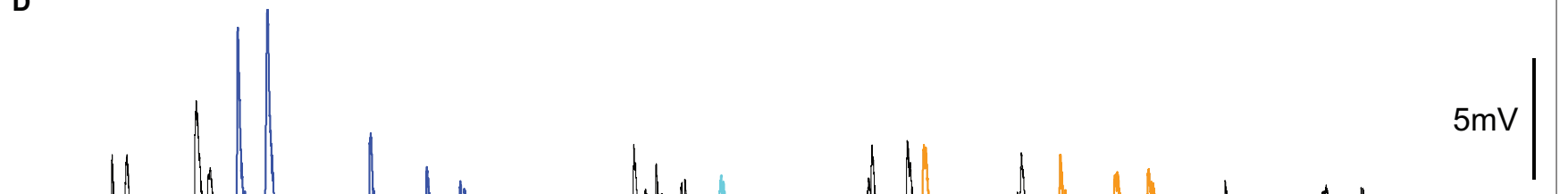
(N)

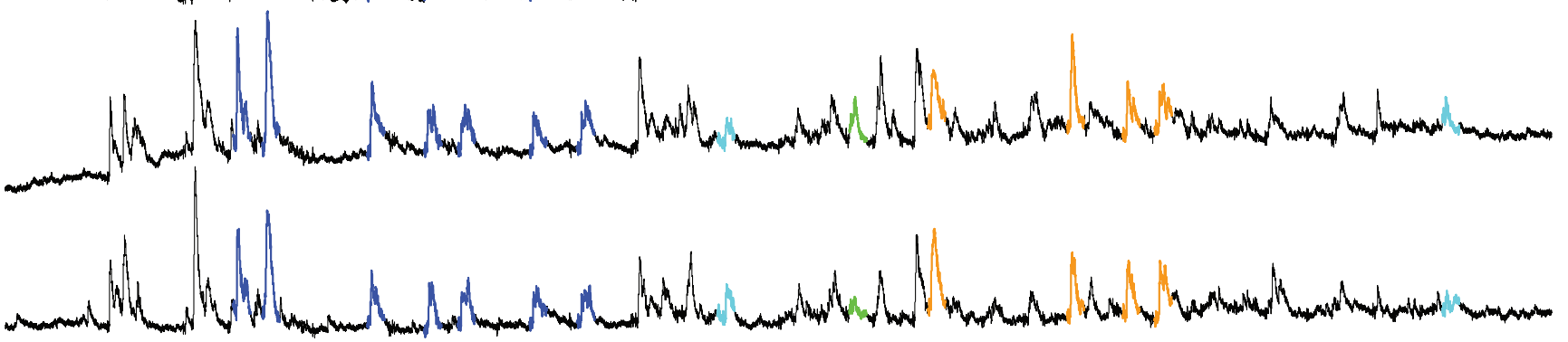
TTX

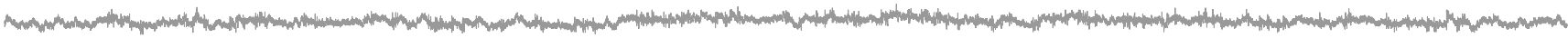

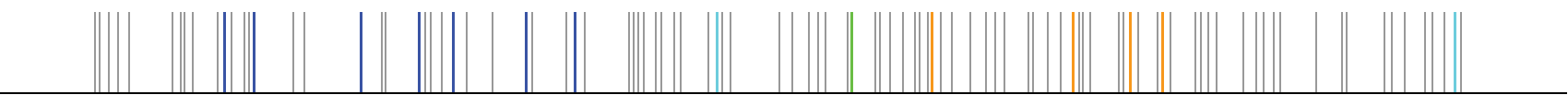

\section{FIGURE 2 | Mapping connectivity utilizing photostimulation: (A)}

Presynaptic neurons (black) are stimulated sequentially in the slice-preparation to fire action potentials by focused uncaging of glutamate via short pulses of UV-light. These APs, in turn, evoke synaptic potentials in the postsynaptic neuron (red), the membrane potential of which is monitored via a patch-clamp electrode (for detailed methods, see Boucsein et al., 2005). (B) Overlay of a picture of a neocortical brain slice and the results from scanning the tissue for functional connections to the postsynaptic neuron (reconstruction shown in red). Squares denote the positions of presynaptic sites, the stimulation of which elicited a postsynaptic current. Colored squares refer to selected sites, highlighted in the corresponding color in (C,D). (C) Principle of dynamic photostimulation (DPS).
Using the fast DPS-system (Boucsein et al., 2005; Nawrot et al., 2009), presynaptic neurons can be activated dynamically to produce patterns of spatiotemporal synaptic input to the postsynaptic cell (red). (D) Dendritic integration in the postsynaptic neuron. Three repetitions of the same stimulation sequence (tics, bottom) resulted in repeated sub-threshold membrane potential fluctuations. Voltage traces for selected presynaptic sites are colored for the first $80 \mathrm{~ms}$ following presynaptic photostimulation, corresponding to the sites, indicated in $\mathbf{( B , C )}$. Note the remarkable reproducibility of the voltage fluctuations across trials. The gray trace shows the response to the same stimulation after application of TTX, confirming the purely synaptic origin of the recorded potentials. 


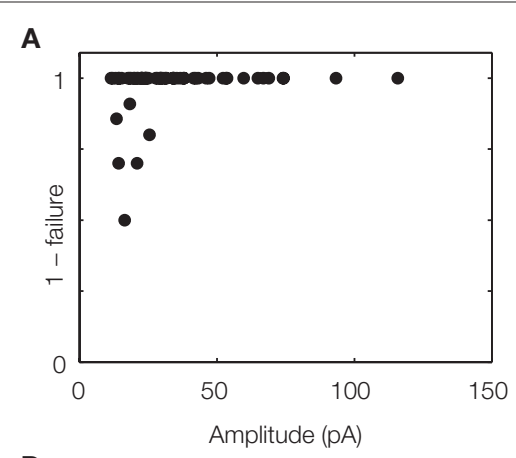

D

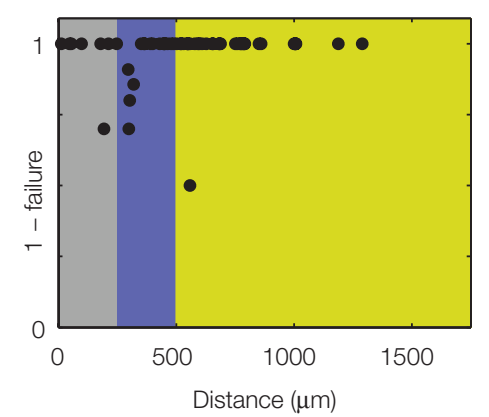

G

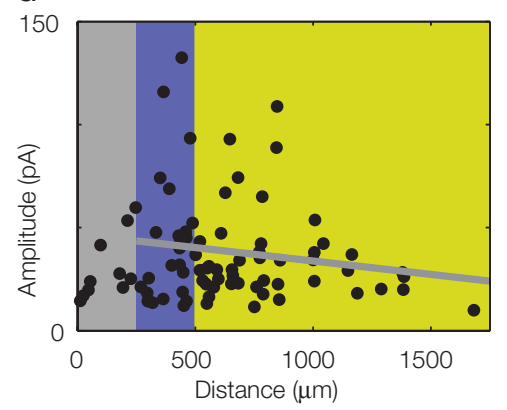

B

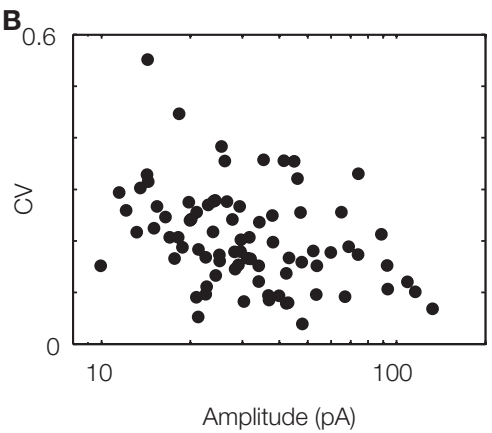

E

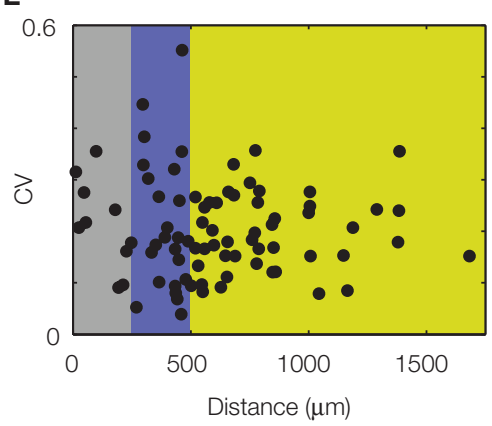

H

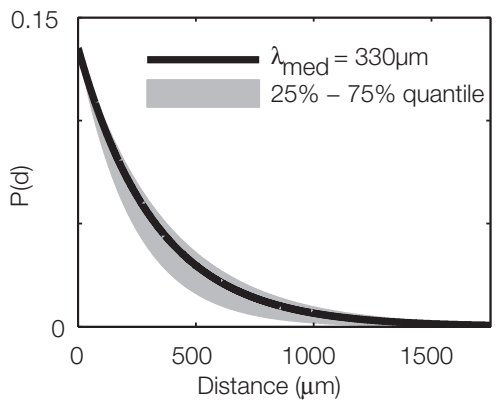

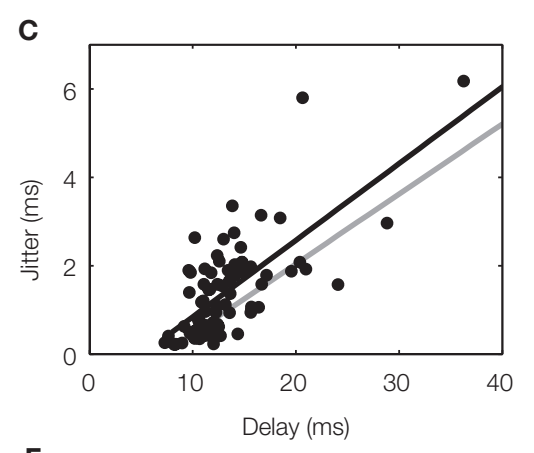

C

$\mathbf{F}$

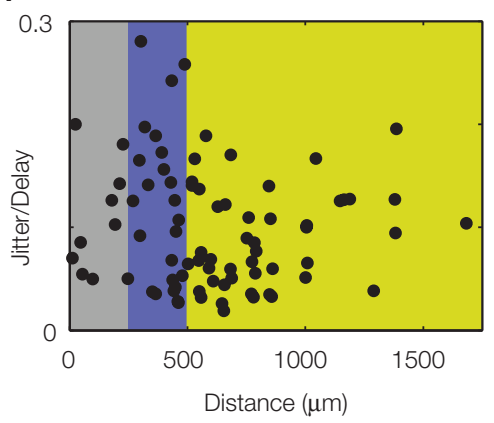

I

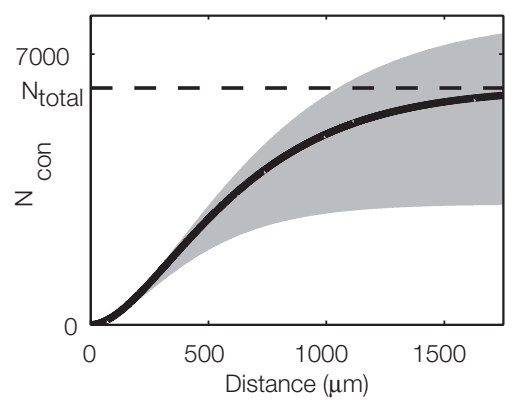

FIGURE 3 | Quantitative, physiological parameters of horizontal connections, determined by dynamic photostimulation (DPS). Presynaptic cells $(n=82)$ were stimulated by laser uncaging of caged glutamate (for details see Nawrot et al., 2009) to fire action potentials. Excitatory postsynaptic currents (EPSCs) were quantified in the cells receiving the projections. (A) Most projections were highly reliable, with failures only apparent in low amplitude EPSCs. (B) Relative amplitude variability, expressed as the coefficient of variation (CV) of the EPSC amplitude, had a clear tendency to decrease with increasing amplitude. (C) Temporal jitter, measured as the standard deviation of EPSC threshold crossing times after stimulation onset, scales with the delay between stimulation onset and EPSC onset. Quantification of timing of action potential generation for a set of directly stimulated cells (putative presynaptic cells) revealed that most of the jitter in EPSC timing was due to the variability in spike generation. Comparison of regression lines for presynaptic (gray) and postsynaptic (black) jitter suggests that only about $0.5 \mathrm{~ms}$ jitter is actually due to synaptic physiology. (D-G) Lateral distance from the stimulation site to the soma of the postsynaptic cells was extracted for each tested connection to evaluate possible distance dependence of physiological connection parameters. Failure rate (D), amplitude variability (E), and synaptic jitter (normalized to the total delay) (F) did not show any distance dependence, whereas amplitude (G) scaled negatively with distance. Colors correspond to cylindrical volumes, sketched in Figure $\mathbf{4}(\mathbf{H})$. To evaluate the lateral distance dependence of connection probability, we re-analyzed 17 mapping experiments, which were initially performed to find presynaptic sites for dynamic stimulation (compare to Figure 2B). Width of the scanning raster was $100 \mu \mathrm{m}$, and for each horizontal distance, we collected the number of sites, stimulation of which resulted in a postsynaptic EPSC. The ratio of this number relative to the total number of stimulations at the corresponding distance was taken as the estimated connection probability at that distance ( $n=674$ EPSCs in total). When stimulation sites were close to the soma or apical dendrite, EPSCs were often masked by large currents from uncaged glutamate impinging directly on the postsynaptic cell (direct responses). Probed distances where more than $20 \%$ of stimulated sites showed such direct responses were excluded from the analysis. Since it remains unknown how many neurons we stimulated at each target site and it was, thus, only possible to extract relative connection probabilities, we defined $P_{100}=0.1$ at a distance of $100 \mu \mathrm{m}$, as suggested by paired recording studies (see Table 1). Our model of exponential decay is, thus, constrained as $P(d)=P_{0} \cdot \exp (-d / \lambda)$. Single fits were performed for each experiment, and length constants $\lambda$ were extracted. The panel shows an exponential decay with a length constant equal to the median of all extracted $\lambda$-values (black trace), upper and lower shaded regions mark the 75 and $25 \%$ quantile, respectively. (I) Accumulated number of connected cells as a function of lateral distance $d$ from the soma: we estimated the number of connected neurons within a cylindric volume with radius $d$ as $N_{\text {con }}(d)=2 \pi \rho f_{E} h \int_{0}^{d} P(s) s d s$, with $\rho=60,000 / \mathrm{mm}^{3}$ (black trace) defining the cell density per cortex volume, $f_{\mathrm{E}}=0.85$ representing the relative fraction of excitatory connections (Braitenberg and Schüz, 1998), and $h=1.3 \mathrm{~mm}$ defining the thickness of the gray matter. The estimated total number of presynaptic cells then amounts to $N_{\text {totalo }} \sim 6,100$ with $\lambda$ of $330 \mu \mathrm{m}$ (black trace; shaded regions mark total cell numbers for respective $\lambda$ taken from the shaded region in $\mathbf{H}$ ). 
Horizontal connections

In contrast to vertical projections across layers, horizontal connections in neocortical networks can span up to several millimeters and connect different areas or sensory modalities in a non-trivial fashion. They have been implicated in feed-forward and feedback circuits throughout cortex, as well as in binding of different information streams during associative processes and higher brain functions.

\section{Column}

This slightly ambiguous term loosely describes the concept of vertically arranged groups of cells that share certain functional and/or anatomical properties and could represent a "basic functional unit" in cortical processing. They are ubiquitous in the brain but in no way obligatory, and a comprehensive description of the various forms of "columns" in the brain is still lacking.

\section{Photostimulation}

Photostimulation is a technique using photolabile or "caged" precursors of neurotransmitters such as glutamate, which can be rapidly activated by short pulses of light. In acute brain slices, one can map the functional connectivity within the tissue by activating presynaptic cells to fire APs while monitoring the membrane potential of a postsynaptic target cell. our study we focused on horizontal connections ( 200-1500 $\mu \mathrm{m}$ distance in the direction parallel to the pia), whereas classical paired recording experiments were almost exclusively performed within the local range around the postsynaptic neuron $(<250 \mu \mathrm{m}$ distance), where strong vertical connectivity across laminae dominates (Lorento De Nó, 1949; Thomson and Bannister, 2003). To clarify this issue, we re-analyzed the lateral distance dependence of physiological parameters of the synaptic connections studied in our experimental paradigm. We found that the only parameter showing a systematic decrease with lateral distance was the excitatory postsynaptic current (EPSC) amplitude (Figure 3G), whereas other parameters of synaptic physiology did not show such systematic dependence at all (Figures 3D-F).

As a result, our findings raised two main questions: Can horizontal connections be considered to play an important role in cortical processing and, if so, what is actually known about their physiological properties (apart from the limited data available from our previous study)? Here we will undertake first steps to answer these questions.

\section{THE FRACTION OF HORIZONTAL PROJECTIONS ONTO PYRAMIDAL CELLS}

Since the seminal work of Mountcastle (1955, 1957) and Hubel and Wiesel (1962), showing that neurons along a path perpendicular to the cortical surface share functional properties of stimulus selectivity, the idea of a columnar structure defining generic building blocks for larger cortical networks has attracted many scientists (for recent reviews see da Costa and Martin, 2010; Rockland, 2010; and other contributions to the special issue on "The Neocortical Column" in Frontiers in Neuroanatomy). In the attempt to understand information processing in local cortical circuits, a well-established and ever more detailed description of the underlying functional architecture has been generated (for reviews see Thomson and Bannister, 2003; Markram, 2006; Douglas and Martin, 2007). In the course of these attempts, the original concept of columnar organization has been interpreted in quite different ways. While initially, common functional tuning properties in cat visual cortex were used to assign cells to the same column, later the intricate anatomical structures in layer IV of the somatosensory cortex in rodents (so-called barrels) were also utilized to define column boundaries. It has been debated whether both assignments refer to the same conceptual idea (for a review see Horton and Adams, 2005), especially since in visual areas of rat cortex the clustering of similarly tuned cells is not apparent (Ohki et al., 2005). In contrast to these various considerations on the vertical organization of cortical circuits, horizontal connections received much less attention in experimental and theoretical work (for a recent review see Voges et al., 2010b).

The experimental confinement to a projection range of approximately $250 \mu \mathrm{m}$ around the somato-dendritic axis of the pyramidal neurons (Deuchars et al., 1994; Markram et al., 1997; Lefort et al., 2009) and to vertical projections across laminae (for a review see Thomson and Lamy, 2007) is not solely due to a conceptual focus on local connections. In addition, the strong drop in connection probability with increasing somatic distance between cell pairs (Hellwig, 2000; Thomson and Bannister, 2003) imposes experimental constraints that make the physiological characterization of synaptic connections with paired recordings increasingly difficult at longer distances (however, see Yoshimura et al., 2000). This effect is augmented by the fact that paired recordings are usually conducted in acute brain slices, where sizeable portions of axonal arbors are cut, lowering the chances of finding distant pairs of connected cells even further (Stepanyants et al., 2009).

At first glance, low connection probabilities to distant neurons might imply that connections from more distant cells are rare and, thus, might not play a major role in cortical processing. However, in their extensive study comparing neuronal subtypes in cat $\mathrm{V} 1$ with respect to their laminar distributions of dendrites and synapses, Binzegger et al. (2004) reported large numbers of excitatory synapses, especially in layers I (93\%) and VI (70\%), that remained "unaccounted for." Presumably, these synapses reflect the bulk of extra-columnar input which could not be allocated to any of the cells within their model, as the anatomical reconstructions used in their study only contained the local axonal arborization (diameter: $\sim 1000 \mu \mathrm{m}$ ), whereas projections of longer distance were cut. Other studies recognized that, despite low connection probabilities, the total number of potential presynaptic cells still might increase for larger distances, simply due to the quadratic increase in the number of potential partners (Hellwig, 2000; Holmgren et al., 2003). In another recent study, estimates of the fractions of local (columnar) and non-local connections suggested that up to $82 \%$ of the synapses a neuron receives may originate from cells outside the cortical column, i.e., a cylindrical volume with a diameter of $\sim 500 \mu \mathrm{m}$ (Stepanyants et al., 2009; see also Figure 4). The same study suggested that even if the cortical volume covered by the dense 


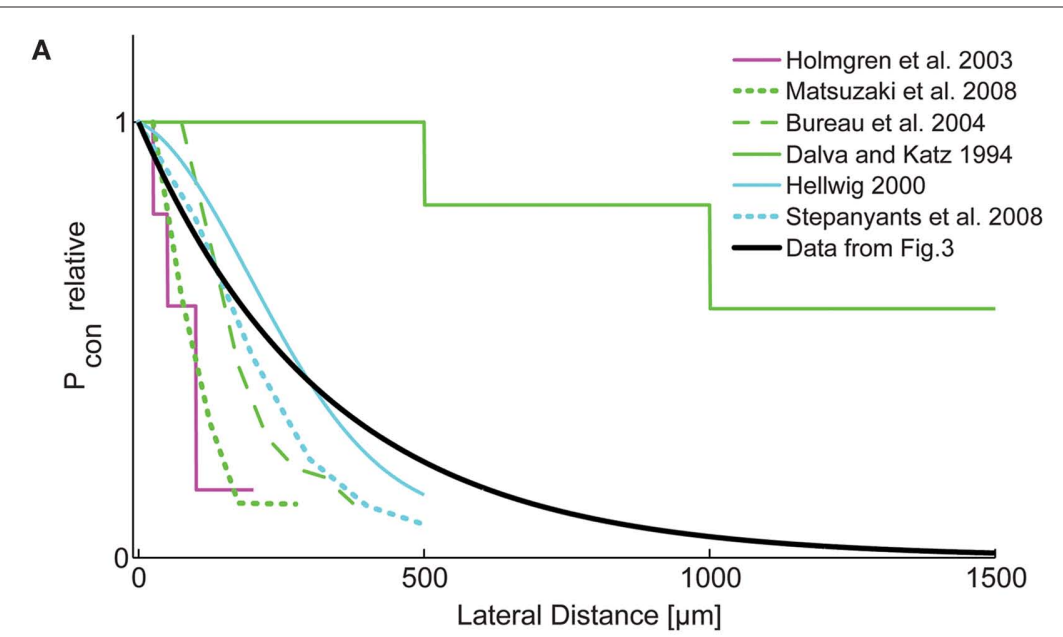

C

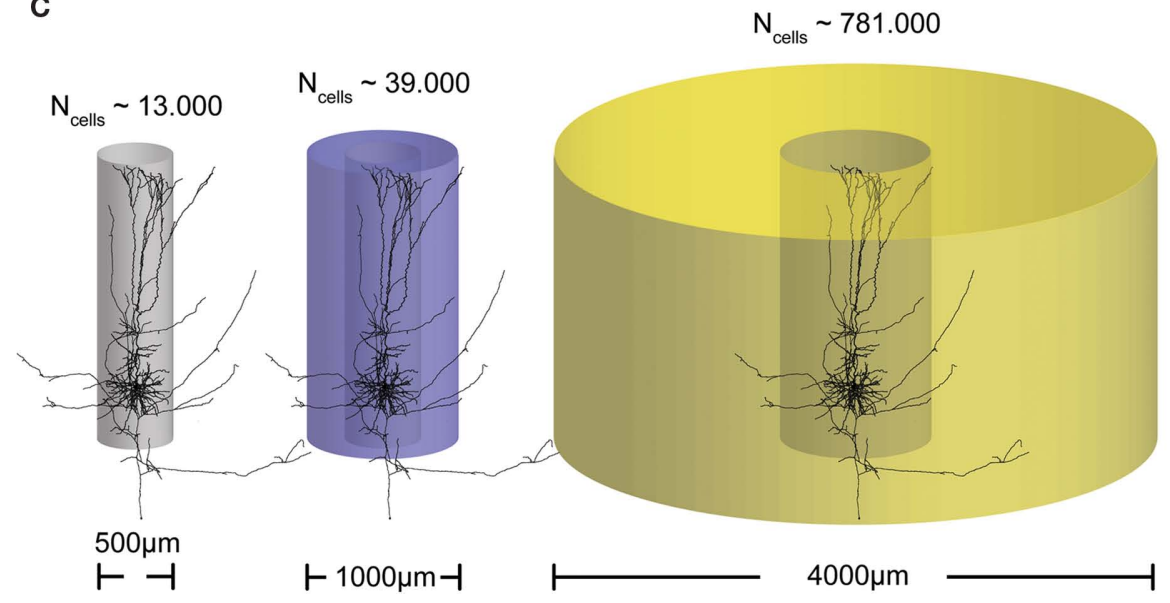

B

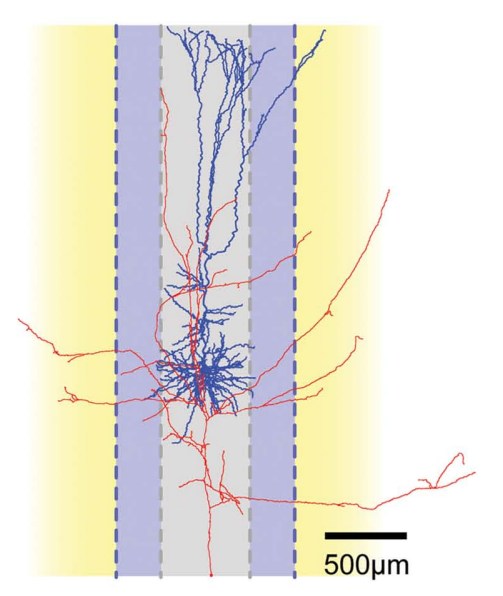

D

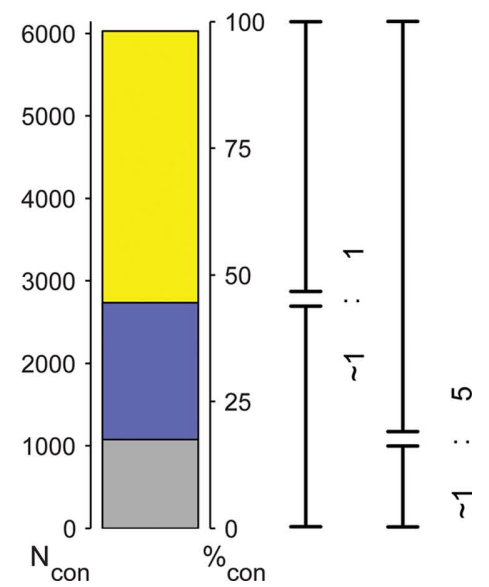

FIGURE 4 | Distribution of presynaptic cells within the cortical volume. (A) Graphical representation of connection probability as a function of lateral distance, comparing results from different studies. Methodological problems prevent direct numerical comparison. We, thus, normalized the maximum $P_{\text {con }}$ found in each study to unity and plotted one representative curve from each study into a single summary plot. Clearly, the length constant of the spatial decay of $P_{\text {con }}(d)$ derived from our data (black trace, cf. Figure $\mathbf{3 H}$ ) fits well within the range reported by these previous studies. (B) Morphological reconstruction of a layer $\mathrm{V}$ pyramidal cell from a recording in an acute slice of $300 \mu \mathrm{m}$ thickness with dendritic (blue) and axonal (red) arborizations. Following earlier work (Stepanyants et al., 2009), two definitions of locality can be derived from the neuronal morphology: either the volume covered by the dendrites (diameter of approximately $500 \mu \mathrm{m}$, gray), or, alternatively, by the dense axonal plexus around the somato-dendritic axis (diameter of approximately $1000 \mu \mathrm{m}$, blue). (C) The number of possible presynaptic partners $\left(N_{\text {cells }}\right)$ increases substantially with distance, due to the quadratic increase of the volume covered by cylinders with increasing radius. This implies that the number of connected cells does not necessarily decrease with increasing distance, even if connection probability drops substantially. (D) To emphasize the consequences of the described distance dependence of $P_{\text {con }}$ for the total number of actually connected presynaptic cells within a certain distance, we calculated the numbers of these synaptically connected cells for the three different ranges depicted in (C). For all volumes, we used our exponential decay model with $\lambda=330 \mu \mathrm{m}$ and $P_{0}=0.135$ and, again, assumed a thickness of cortical gray matter of $1.3 \mathrm{~mm}$. Surprisingly, even with a strong decay in $P_{\text {con }}(d)$ with increasing distance, the majority of presynaptic cells are located outside the local volume. Depending on the definition of locality, at least half of the synapses on each cell (local = diameter of $1000 \mu \mathrm{m}$ ), or more than $80 \%$ (local $=$ diameter of $500 \mu \mathrm{m}$ ) originate from cells not considered to be within the local volume. The total number of presynaptic cells is slightly higher than what can be expected to be contained in a cylinder of $4000 \mu \mathrm{m}$ diameter [cf. extent of the bar in (D) does not account for $100 \%$ ]. axon plexus around the somato-dendritic axis is considered (a cylinder with diameter $\sim 1000 \mu \mathrm{m}$ ), the fraction of synapses originating from outside this volume may amount to $75 \%$.

To test these various predictions on our data, we carefully re-analyzed the photostimulation experiments in which we scanned acute brain slices for neurons projecting onto a single postsynaptic cell (Nawrot et al., 2009). For each horizontal distance from the cell soma, probed in bin-wise intervals of $100 \mu \mathrm{m}$, we measured the number of sites, the stimulation of which resulted in an EPSC measured at the soma. Then, for each of these distances, we estimated the connection probability as the ratio of 
this number of effective stimulation sites relative to the total number of stimulations at this distance. To the collection of these connection probability estimates as a function of lateral distance we then fitted an exponential decay function for each mapping experiment separately. From this fit, we determined the associated space constant for each experiment. The resulting space constants of connectivity decay with distance varied between 165 and $665 \mu \mathrm{m}$. Using the median value of $330 \mu \mathrm{m}$ (Figure $3 \mathbf{H}$ ) and constraining our model of exponential decay by introducing a fixed value for the local connection probability of 0.1 at $100 \mu \mathrm{m}$ (derived from the literature on paired recordings), we then calculated the potential numbers of presynaptic neurons as a function of somatic distance (Figure 3I). Under the simplifying assumptions of homogeneity and isotropy and adopting a cylindrical layout of the connectivity (cf. Figure 4C), the number of neurons at a certain distance providing input to a postsynaptic cell at the center of the cylinder is proportional to the product of the cell density $(\sim 60-90,000$ neurons/mm $\mathrm{mm}^{3}$ in rat V1; Peters et al., 1985; Gabbott and Stewart, 1987; Skoglund et al., 1996; Miki et al., 1997), multiplied by the fraction of excitatory cells, the thickness of the gray matter, the distance itself, and the respective connection probability (Figure 3I). Integration over the distance from 0 (soma) outward to a certain distance $d$ from the soma then leads to an estimate of the total number of presynaptic neurons within that distance, that is, the number of neurons that provide synaptic input to the recorded cell (Figure 3I). Interestingly, from this calculation it follows that the local volume around a layer V pyramidal cell $(r=250 \mu \mathrm{m})$ contains less than $25 \%$ of its presynaptic partners. Even if a larger distance of $500 \mu \mathrm{m}$ is considered (as in Stepanyants et al., 2009), this fraction still amounts to less than 50\% (Figure 4D).

These results are somewhat difficult to relate to other studies reporting on distance dependence of connection probability in neocortical networks, mostly because in the experimental studies on horizontal connectivity available to date, very different methods were employed, ranging from paired recordings over laser scanning approaches to modeling studies using morphological reconstructions (for references, see Table $\mathbf{1}$ ). In addition, most studies were restricted to distances of less than $250 \mu \mathrm{m}$, while our data span a range almost ten times as big. One exception is the study of Shepherd et al. (2005), where the authors

Table 1 | Overview of studies on lateral distance dependence of connection probability $P_{\text {con }}(d)$ within the neocortex.

\begin{tabular}{|c|c|c|c|c|c|}
\hline Range $(\mu \mathrm{m})$ & Pcon* & Method & Measure & Species & Reference \\
\hline $0-200$ & $0.1-0.01$ & $\begin{array}{l}\text { Paired recordings } \\
\text { in acute slices }\end{array}$ & $\begin{array}{l}\text { Connection probability } \\
\text { (tested pairs) }\end{array}$ & $\begin{array}{l}\text { Rat V1/S1 cat V1 } \\
\text { all layers }\end{array}$ & $\begin{array}{l}\text { Markram et al. (1997); } \\
\text { Thomson et al. (2002); } \\
\text { Holmgren et al. (2003); Song et al. } \\
\text { (2005); Lefort et al. (2009) }\end{array}$ \\
\hline $0-300$ & $0.1-0.01$ & $\begin{array}{l}\text { Two-photon } \\
\text { laser uncaging }\end{array}$ & $\begin{array}{l}\text { Responding sites normalized } \\
\text { to putative presynaptic cells }\end{array}$ & Rat V1 layer 2/3 & Matsuzaki et al. (2008) \\
\hline $0-400$ & $1-0.13$ & Laser uncaging & $\begin{array}{l}\text { Integral of postsynaptic } \\
\text { currents }\end{array}$ & $\begin{array}{l}\text { Rat barrel cortex } \\
\text { layer } 2 / 3\end{array}$ & Bureau et al. (2004) \\
\hline $0-1500$ & $0.21-0.12$ & Laser uncaging & $\%$ of responding sites & Ferret V1 all layers & Dalva and Katz (1994) \\
\hline $300-1500$ & $0.45-0.028$ & Laser uncaging & $\%$ of responding sites & Rat S1 all layers & This study \\
\hline $0-500$ & $0.86-0.12$ & $\begin{array}{l}\text { Computing possible } \\
\text { synapses from } \\
\text { reconstructions }\end{array}$ & $\begin{array}{l}\text { Connection probability } \\
\text { (anatomical) }\end{array}$ & Rat $\mathrm{V} 1$ layer $12 / 3$ & Hellwig (2000) \\
\hline $0-500$ & $0.75-0.06$ & $\begin{array}{l}\text { Computing possible } \\
\text { synapses from } \\
\text { reconstructions }\end{array}$ & $\begin{array}{l}\text { Connection probability } \\
\text { (anatomical) }\end{array}$ & Cat V1 all layers & Stepanyants et al. (2008) \\
\hline
\end{tabular}

Only a few studies have focused on this issue, most of them being limited to distances up to 300 mm from the somato-dendritic axis of the cells. Note that methodologies in these studies were quite diverse, and quantitative measures of connectivity cannot easily be compared. The most direct quantification was obtained by paired recordings (magenta), when experimenters kept track of the total numbers of tested cells and related these to the numbers of connected cells found. Interestingly, most studies performed with paired recordings within the neocortex yielded a maximum $P_{\text {con }}$ in the order of 0.1 within the column. We used this value to constrain our model of exponential decay (Figure $\mathbf{3 H}$ ). Mapping studies with glutamate uncaging (green), on the other hand, have to cope with three major complications: firstly, given high connection probabilities, inputs from multiple presynaptic cells might coincide after stimulation of one site, yielding compound responses which may be difficult to separate. Secondly, careful calibration experiments need to be performed to estimate the total number of cells per site that fire an action

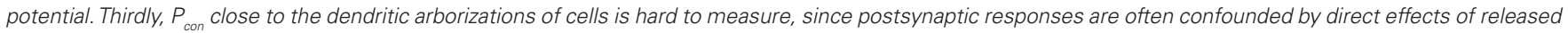

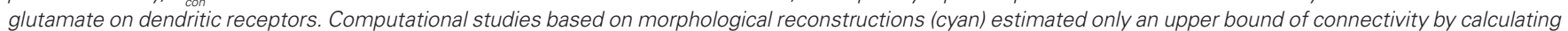

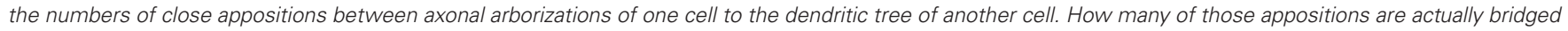
by synapses can only be estimated (by the so-called "filling factor").

${ }^{*}$ Non-normalized values. 
combined connectivity measures derived from functional mapping via photostimulation and 3D morphological reconstructions for distances of up to $700 \mu \mathrm{m}$ to assess whether it is sufficient to rely on anatomical data to determine the connectivity in rat barrel cortex. They concluded that neuronal specificity (e.g., type and position of pre- and postsynaptic neuron, amongst other factors) prevented direct comparability of these two measures. However, in their study, the authors largely focused on specific connections from L4/ L5A to L2/3 pyramidal neurons across the laminar borders. For this reason, we included a previous study from the same group (Bureau et al., 2004), dealing with horizontal connectivity in L2/3 in our Figure 4. To compare results across studies, we normalized the various experimental findings on distance-dependent connection probabilities to the maximum connection probability in each case. This enabled us to include results from all these different studies within a single graphical representation (Figure 4A). Apparently, connection probability decay functions vary considerably, but they all seem to follow a similar law, reasonably well approximated by an exponential decay, as fitted to our data. Moreover, the calculations above suggest that, also in other preparations, nonlocal (i.e., from beyond $250 \mu \mathrm{m}$ lateral distance) presynaptic cells account for more than $70 \%$ of the total number of synaptic inputs onto a pyramidal cell (Figure 4D; see also Voges et al., 2010b). Possible sources for unaccounted synapses include horizontal projections connecting neighboring columns, e.g., via L2/3 pyramidal neurons in primary visual cortex (Tucker and Katz, 2003; Buzás et al., 2006) or barrel cortex (Brecht et al., 2003; Lübke and Feldmeyer, 2007; Bruno et al., 2009), as well as far-reaching axon collaterals from L5/ L6 neurons within the same cortical area (Larsen et al., 2007). In the present study, we are focusing on these intra-cortical, horizontal projections. In addition, projections connecting different sensory areas and, e.g., thalamo-cortical, cortico-cortical, or inter-hemispheric connections (Cauller et al., 1998; Petreanu et al., 2007; Rubio-Garrido et al., 2009) need to be taken into account when referring to the total number of synaptic contacts a neuron receives. These connections have been shown to link stimulus features across columnar boundaries or sensory areas for different modalities and in different species (Mitchison and Crick, 1982; Weliky and Katz, 1994; Singer, 1999; Staiger et al., 2004; Buzás et al., 2006; Huber et al., 2008).

The fact that only a small fraction of the axons synapsing onto a neuron originate from cells within the local volume implies that, by concentrating on the local circuit alone, one is likely to ignore important aspects of cortical processing. In fact, the concept that information processing within the neocortex is based on columnar microcircuits has been challenged by studies showing that the lack of a columnar architecture does not impede the functionality of cortical neurons (Purves et al., 1992), and that the extent to which a columnar structure can be observed may vary substantially, even between individuals of the same species (Horton and Adams, 2005; Rockland, 2010). In addition, many studies on local connectivity have been performed in acute slices of rats and mice, where the concept of columns consisting of similarly tuned cells is, at least in the visual cortex, not easily applicable (Ohki et al., 2005). Thus, it is of key importance to gain more insight into the nature (both, physiological and anatomical) of horizontal connections in neocortical networks. The investigation of these connections is merely beginning.

\section{PHYSIOLOGICAL CHARACTERIZATION OF HORIZONTAL PROJECTIONS}

So far, details about horizontal connections in cortex have mainly been revealed by tracer injection studies (Burkhalter, 1989; Kisvárday et al., 1989; Kisvárday and Eysel, 1992; Lund et al., 1993; Van Hooser et al., 2006; Aronoff et al., 2010; reviewed in Voges et al., 2010b). These anatomical studies, however, did not deliver any information about the physiological properties of these connections. More recently, voltage-sensitive dyes (Laaris and Keller, 2002; Petersen et al., 2003; Tucker and Katz, 2003) and $\mathrm{Ca}^{2+}$-imaging (Göbel et al., 2007) have been used to study the role of long-range connections in vitro and in vivo, again providing only limited information on the physiology of single connections. Only few physiological studies, using electrical stimulation, report on selected physiological aspects of horizontal connections (Chagnac-Amitai and Connors, 1989; Ichinose and Murakoshi, 1996). The only studies that focused on the physiological properties of putative horizontal projections in the neocortex were performed either in vivo with the help of intracellular recordings in combination with extracellular stimulation (Matsumura et al., 1996) or in acute slices with a combination of intracellular recordings and juxtacellular stimulation (Yoshimura et al., 2000). In both these studies, synaptic connections between sites with a distance of up to $2 \mathrm{~mm}$ were characterized by spike-triggered averaging or paired recordings, and, in line with our findings (Figure 3G), they reported that synaptic PSP amplitude dropped slightly with increasing distance between connected cells. However, their finding of a decrease in synaptic reliability with increasing distance is in contrast with our finding of reliable horizontal 
connections (Figure 3D). Moreover, the results of the in vivo studies need to be interpreted with caution, because it is difficult to extract information about mono-synaptic connections in a recurrent, densely connected, active network from spike-triggered averages. Here, network effects can lead to responses that resemble PSPs from mono-synaptic connections, even though the respective cells are not directly connected. Actually, such PSP-shaped responses with sometimes negative latency with respect to the trigger unit have been experimentally observed (Matsumura et al., 1996), as well as theoretically predicted (Aertsen et al., 1989, 1994; Kumar et al., 2008). Yoshimura et al. (2000) focused on short-term plasticity of long-distance synaptic connections and reported only limited data on other parameters, like PSP amplitudes or synaptic reliability, and no information at all on connection probability. Photostimulation of selected subsets of neurons in acute brain slices (Callaway and Katz, 1993; Dodt et al., 2003; Kötter et al., 2005; Fino et al., 2009), as used in our study (Nawrot et al., 2009), seems to be one of the few methods available today that has been employed successfully to study the physiology of horizontal connections in greater detail (Shepherd et al., 2005; Matsuzaki et al., 2008). The methodological limitations of this technique are mainly that it is technically challenging to acquire maps with cellular resolution, that the number of stimulations of the same presynaptic site is limited due to detrimental side-effects of the short-wavelength light used for uncaging, and that the identity of the presynaptic cell is usually not recovered, except for its coarse location and the inhibitory or excitatory nature of its synapses (for a discussion see Nawrot et al., 2009). More quantitative experimental data will be necessary to judge whether horizontal connections can also show high failure rates, or if the comparatively high reliability found in our data may indeed be due to special physiological properties, such as multiple synaptic contacts for these connections, or extraordinarily strong single synapses, which would render these connections a suitable substrate for reliable and precise signal propagation in neocortical networks.

\section{FUNCTIONAL IMPLICATIONS}

Horizontal connections within the neocortex are likely to play a pivotal role for cortical processing, purely due to their relative abundance. As is evident from the small number of studies thus far concerned with the physiological properties of horizontal connections, the interest in this large fraction of intra-cortical projections is just beginning. In recent modeling studies, it has been demonstrated that the implementation of horizontal connections can dramatically reduce wiring costs
(Voges et al., 2010a) and has a strong impact on network dynamics (Kriener et al., 2009). These studies, however, focused on a related class of connections, the so-called long-range patchy connections (for a review see Voges et al., 2010b), which recently received more attention compared to non-patchy, long-distance horizontal connections. Patchy connections can be observed after bulk-loading of small volumes, preferentially in primary visual areas of higher mammals, as petal-like clusters of cells presumably receiving functional synaptic input from the injection site. It could be argued that the horizontal connections described in our study might serve the same purpose as patchy connections in higher mammals, but on a different spatial scale. However, detailed comparison of long-range patchy and non-patchy connections has cast doubt on this idea: while correlation strength was found to be high in pairs of similarly tuned neurons connected via longrange patchy connections in cat visual cortex, this was not true for the non-columnar cortex of gray squirrels (Van Hooser et al., 2006; Van Hooser, 2007). Similarly, it was described that the subthreshold membrane potential fluctuations display tuning similar to that of the spiking response in cells within orientation columns, while this has not been found in cells of non-columnar tissue.

What could be the functional relevance of excitatory horizontal connections in the neocortex? A recent study using light-activated cells in vivo suggested that they might be the substrate for a competition between neighboring cortical domains, where strong activity in superficial layers inhibits neighboring domains within the same layer, while spreading excitation to a wide spatial range in deeper layers (Adesnik and Scanziani, 2010). Our findings emphasize that these connections might be especially reliable, strong, and temporally precise (Figure 3 ). Moreover, they indicate that precisely timed horizontal inputs are faithfully represented in the temporal dynamics of the integrated membrane potential of postsynaptic cells (Figure 2; Nawrot et al., 2009). Thus, horizontal connections and precise postsynaptic signal integration can subserve the fast and reliable propagation of correlated spiking over larger intra-cortical distances, at least in a low-firing regime. This combination of anatomy and physiology provides a potential neuronal substrate for neural computations with high temporal precision in the millisecond range, as is required for the realization of various temporal coding schemes (Gerstein et al., 1989; Abeles, 1991; van Rullen and Thorpe, 2002; Gollisch and Meister, 2008; Jacobs et al., 2009; for recent reviews see Harris, 
2005; Kumar et al., 2010). Even though conclusive evidence for the presence of such coding strategies in the brain is still lacking, several studies demonstrated the brain's ability of remarkably fast and precise information processing. When confronted with a classification task, monkeys can signal their correct choice within 140-160 ms after stimulus onset (Fabre-Thorpe et al., 1998), and this short reaction time includes not only cortical processing, but also peripheral vision as well as motor execution. In the same line of evidence, it has been shown that already 150$250 \mathrm{~ms}$ after stimulus presentation, intended movements for the proper trained direction can be extracted from signals from the motor cortex (Rickert et al., 2009). It is unknown in how far horizontal connections are involved in this kind of rapid sensory-motor transformation and decision making, but it seems rather unlikely that the neocortex could process and transfer information in such short times over such large distances, mainly based on local connectivity. In conclusion, therefore, it seems important to incorporate horizontal connections in our considerations for concepts of cortical processing and cortical neural network models.

\section{ACKNOWLEDGMENTS}

This project received funding from the German Federal Ministry of Education and Research (BMBF grants 01GQ0420 to BCCN Freiburg, 01GQ0830 to BFNT Freiburg/ Tübingen, and 01GQ0413 to BCCN Berlin), from the European Union (EU Grant 15879, FACETS) and from the German Research Council (DFG-SFB 780 and DFG-GRK 1589). We thank Claudia Bachmann for help with the reconstruction of neuronal morphologies.

\section{REFERENCES}

Abeles, M. (1991). Corticonics: Neural Circuits of the Cerebral Cortex. Cambridge, MA: Cambridge University Press.

Adesnik, H., and Scanziani, M. (2010). Lateral competition for cortical space by layer-specific horizontal circuits. Nature 464, 1155-1160.

Adrian, E. (1928). The Basis of Sensation. London: Christophers.

Aertsen, A., Erb, M., and Palm, G. (1994). Dynamics of functional coupling in the cerebral cortex: an attempt at a model-based interpretation. Physica D 75, 103-128.

Aertsen, A. M., Gerstein, G. L., Habib, M. K., and Palm, G. (1989). Dynamics of neuronal firing correlation: modulation of "effective connectivity". $J$. Neurophysiol. 61, 900.

Aertsen,A.M.H.J., Smolders, J.W. T., and Johannesma, P. I. M. (1979). Neural representation of the acoustic biotope: on the existence of stimulus-event relations for sensory neurons. Biol. Cybern. 32, 175-185.

Alonso, J. M., Usrey, W. M., and Reid, R. C. (1996). Precisely correlated firing in cells of the lateral geniculate nucleus. Nature 383, 815-819.

Arieli, A., Sterkin, A., Grinvald, A., and Aertsen, A. (1996). Dynamics of ongoing activity: explanation of the large variability in evoked cortical responses. Science 273, 1868-1871.

Aronoff, R., Matyas, F., Mateo, C., Ciron, C., Schneider, B., and Petersen, C. C. H. (2010). Long-range connectivity of mouse primary somatosensory barrel cortex. Eur. J. Neurosci.31, 2221-2233.

Barlow, H. B. (1972). Single units and sensation: a neuron doctrine for perceptual psychology? Perception 1, 371-394.

Binzegger, T., Douglas, R., and Martin, K. (2004). A quantitative map of the circuit of cat primary visual cortex. $J$. Neurosci. 24, 8441-8453.

Boucsein, C., Nawrot, M., Rotter, S. Aertsen, A., and Heck, D. (2005). Controlling synaptic input patterns in vitro by dynamic photo stimulation. $J$. Neurophysiol. 94, 2948-2958.

Braitenberg, V., and Schüz, A. (1998). Cortex: Statistics and Geometry of Neuronal Connectivity. New York: Springer.

Brecht, M., Roth, A., and Sakmann, B. (2003). Dynamic receptive fields of reconstructed pyramidal cells in layers 3 and 2 of rat somatosensory barrel cortex. J. Physiol. 553, 243-265.

Bremaud, A., West, D., and Thomson, A. (2007). Binomial parameters differ across neocortical layers and with different classes of connections in adult rat and cat neocortex. Proc. Natl. Acad. Sci. U.S.A. 104, 14134-14139.

Bruno, R. M., Hahn, T. T. G., Wallace, D. J., de Kock, C. P. J., and Sakmann, B. (2009). Sensory experience alters specific branches of individual corticocortical axons during development. J. Neurosci. 29, 3172-3181.

Bureau, I., Shepherd, G., and Svoboda, K. (2004). Precise development of functional and anatomical columns in the neocortex. Neuron 42, 789-801.

Burkhalter, A. (1989). Intrinsic connections of rat primary visual cortex: laminar organization of axonal projections. J. Comp. Neurol. 279, 171-186.

Buzás, P., Kovács, K., Ferecskó, A. S., Budd, J. M., Eysel, U. T., and Kisvárday, Z. F. (2006). Model-based analysis of exci- tatory lateral connections in the visual cortex. J. Comp. Neurol. 499, 861-881.

Callaway, E., and Katz, L. (1993). Photostimulation using caged glutamate reveals functional circuitry in living brain slices. Proc. Natl. Acad. Sci. U.S.A. 90, 7661-7665.

Cauller, L., Clancy, B., and Connors, B. (1998). Backward cortical projections to primary somatosensory cortex in rats extend long horizontal axons in layer I. J. Comp. Neurol. 390 297-310.

Chagnac-Amitai, Y., and Connors, B. W. (1989). Horizontal spread of synchronized activity in neocortex and its control by GABA-mediated inhibition. $J$. Neurophysiol. 61, 747-758.

Crochet, S., and Petersen, C. C. H. (2006) Correlating whisker behavior with membrane potential in barrel cortex of awake mice. Nat. Neurosci. 9 , 608-610.

da Costa, N. M., and Martin, K. A. C. (2010). Whose cortical column would that be? Front. Neuroanat. 4:16. doi 10.3389/fnana.2010.00016

Dalva, M. B., and Katz, L. C. (1994) Rearrangements of synaptic connections in visual cortex revealed by laser photostimulation. Science 265 255-258.

Deuchars, J., West, D. C., and Thomson, A. M. (1994). Relationships between morphology and physiology of pyramid-pyramid single axon connections in rat neocortex in vitro. J. Physiol. 478 , 423-435.

DeWeese, M., and Zador, A. (2006) Non-Gaussian membrane potential dynamics imply sparse, synchronous activity in auditory cortex. J. Neurosci. 26, 12206-12218.
DeWeese, M. R., Wehr, M., and Zador, A. M. (2003). Binary spiking in auditory cortex. J. Neurosci. 23, 7940.

Diesmann, M., Gewaltig, M., and Aertsen A. (1999). Stable propagation of synchronous spiking in cortical neural networks. Nature 402, 529-533.

Dodt, H., Schierloh, A., Eder, M., and Zieglgänsberger, W. (2003). Circuitry of rat barrel cortex investigated by infrared-guided laser stimulation. Neuroreport 14, 623-627.

Douglas, R. J., and Martin, K. A. (2007). Recurrent neuronal circuits in the neocortex. Curr. Biol. 17, R496-R500.

Fabre-Thorpe, M., Richard, G., and Thorpe, S. (1998). Speed of visual processing in rhesus monkeys performing a go/no-go categorization task. Curr. Psychol. Cogn. 17, 1053-1054.

Feldmeyer, D., Egger, V., Lübke, J., and Sakmann, B. (1999). Reliable synaptic connections between pairs of excitatory layer 4 neurones within a single 'barrel' of developing rat somatosensory cortex. J. Physiol. 521, 169-190.

Feldmeyer, D., Lübke, J., and Sakmann, B. (2006). Efficacy and connectivity of intracolumnar pairs of layer $2 / 3$ pyramidal cells in the barrel cortex of juvenile rats. J. Physiol. 575, 583-602.

Field, D. J. (1987). Relations between the statistics of natural images and the response properties of cortical cells. J. Opt. Soc. Am. A 4, 2379-2394.

Fino, E., Araya, R., Peterka, D. S., Salierno, M., Etchenique, R., and Yuste, R. (2009). RuBi-Glutamate: two-photon and visible-light photoactivation of neurons and dendritic spines. Front. Neural Circuits 3:2. doi: 10.3389/ neuro.04.002.2009 
Frick, A., Feldmeyer, D., Helmstaedter, M., and Sakmann, B. (2008). Monosynaptic connections between pairs of L5A pyramidal neurons in columns of juvenile rat somatosensory cortex. Cereb. Cortex 18, 397-406.

Gabbott, P., and Stewart, M. (1987). Distribution of neurons and glia in the visual cortex (area 17) of the adult albino rat: a quantitative description. Neuroscience 21, 833-845.

Gerstein, G., Bedenbaugh, P., and Aertsen, A. (1989). Neuronal assemblies. IEEE Trans. Biomed. Eng. 36, 4-14.

Göbel, W., Kampa, B. M., and Helmchen, F. (2007). Imaging cellular network dynamics in three dimensions using fast 3D laser scanning. Nat. Methods 4, 73-79.

Gollisch, T., and Meister, M. (2008). Rapid neural coding in the retina with relative spike latencies. Science 319, 1108-1111.

Gulledge, A. T., Kampa, B. M., and Stuart, G. J. (2005). Synaptic integration in dendritic trees. J. Neurobiol. 64, 75-90.

Haider, B., Krause, M. R., Duque, A., Yu, Y., Touryan, J., Mazer, J. A., and McCormick, D. A. (2010). Synaptic and network mechanisms of sparse and reliable visual cortical activity during nonclassical receptive field stimulation. Neuron 65, 107-121.

Harris, K. D. (2005). Neural signatures of cell assembly organization. Nat. Rev. Neurosci. 6, 399-407.

Häusser, M., Spruston, N., and Stuart, G. J. (2000). Diversity and dynamics of dendritic signaling. Science 290, 739.

Hellwig, B. (2000). A quantitative analysis of the local connectivity between pyramidal neurons in layers $2 / 3$ of the rat visual cortex. Biol. Cybern. 82, 111-121.

Holmgren, C., Harkany, T., Svennenfors, B., and Zilberter, Y. (2003). Pyramidal cell communication within local networks in layer $2 / 3$ of rat neocortex. $J$. Physiol. 551, 139-153.

Horton, J. C., and Adams, D. L. (2005). The cortical column: a structure without a function. Philos. Trans. R. Soc. Lond., B, Biol. Sci. 360, 837-862.

Hromádka, T., DeWeese, M. R., and Zador, A. M. (2008). Sparse representation of sounds in the unanesthetized auditory cortex. PLoS Biol. 6, e16. doi: 10.1371/ journal.pbio.0060016

Hubel, D. H., and Wiesel, T. N. (1962). Receptive fields, binocular interaction and functional architecture in the cat's visual cortex. J. Physiol. 160, 106-154.

Huber, D., Petreanu, L., Ghitani, N., Ranade, S., Hromádka, T., Mainen, Z., and Svoboda, K. (2008). Sparse optical microstimulation in barrel cortex drives learned behaviour in freely moving mice. Nature 451,61-64.
Ichinose, T., and Murakoshi, T. (1996). Electrophysiological elucidation of pathways of intrinsic horizontal connections in rat visual cortex. Neuroscience 73, 25-37.

Jacobs, A. L., Fridman, G., Douglas, R. M., Alam, N. M., Latham, P., Prusky, G. T., and Nirenberg, S. (2009). Ruling out and ruling in neural codes. Proc. Natl. Acad. Sci. U.S.A. 106, 5936.

Kisvárday,Z., and Eysel, U. (1992). Cellular organization of reciprocal patchy networks in layer III of cat visual cortex (area 17). Neuroscience 46, 275-286.

Kisvárday, Z. F., Cowey, A., Smith, A. D. and Somogyi, P. (1989). Interlaminar and lateral excitatory amino acid connections in the striate cortex of monkey. J. Neurosci. 9, 667-682.

Koester, H. J., and Johnston, D. (2005). Target cell-dependent normalization of transmitter release at neocortical synapses. Science 308, 863.

Kötter, R., Schubert, D., DyhrfjeldJohnsen, J., Luhmann, H. J., and Staiger, J. F. (2005). Optical release of caged glutamate for stimulation of neurons in the in vitro slice preparation. J. Biomed. Opt. 10, 3-15.

Kriener, B., Helias, M., Aertsen, A., and Rotter, S. (2009). Correlations in spiking neuronal networks with distance dependent connections. J. Comput. Neurosci. 27, 177-200.

Kumar, A., Rotter, S., and Aertsen, A. (2008). Conditions for propagating synchronous spiking and asynchronous firing rates in a cortical network model. J. Neurosci. 28, 5268-5280.

Kumar, A., Rotter, S., and Aertsen, A. (2010). Spiking activity propagation in neuronal networks: reconciling different perspectives on neural coding. Nat. Rev. Neurosci. 11, 615-627.

Laaris, N., and Keller, A. (2002). Functional independence of layer IV barrels. J. Neurophysiol. 87, 1028-1034.

Larsen, D. D., Wickersham, I. R., and Callaway, E. M. (2007). Retrograde tracing with recombinant rabies virus reveals correlations between projection targets and dendritic architecture in layer 5 of mouse barrel cortex. Front. Neural Circuits 1:5. doi: 10.3389/ neuro.04.005.2007

Las, L., Stern, E. A., and Nelken, I. (2005) Representation of tone in fluctuating maskers in the ascending auditory system. J. Neurosci. 26, 1503-1513.

Lefort, S., Tomm, C., Floyd Sarria, J., and Petersen, C. C. (2009). The excitatory neuronal network of the $\mathrm{C} 2$ barrel column in mouse primary somatosensory cortex. Neuron 61, 301-316.

Levy, W. B., and Baxter, R. A. (1996). Energy efficient neural codes. Neural. Comput. 8, 531-543.

Lorento De Nó, R. (1949). "Cerebral cortex: architecture, intracortical connections, motor projections," in Physiology of the Nervous System, ed. J. Fulton (New York: Oxford University Press), 288-330.

Lübke, J., and Feldmeyer, D. (2007). Excitatory signal flow and connectivity in a cortical column: focus on barre cortex. Brain Struct. Funct. 212, 3-17.

Lund, J. S., Yoshioka, T., and Levitt, J. B. (1993). Comparison of intrinsic connectivity in different areas of macaque monkey cerebral cortex. Cereb. Cortex 3, 148-162.

Maldonado, P., Babul, C., Singer, W. Rodriguez, E., Berger, D., and Grün, S. (2008). Synchronization of neuronal responses in primary visual cortex of monkeys viewing natural images. $J$. Neurophysiol. 100, 1523-1532.

Margrie, T., Brecht, M., and Sakmann, B. (2002). In vivo, low-resistance, wholecell recordings from neurons in the anaesthetized and awake mammalian brain. Pflugers Arch. Eur. J. Physiol. 444 491-498.

Markram, H. (2006). The blue brain project. Nat. Rev. Neurosci. 7, 153-160.

Markram, H., Lubke, J., Frotscher, M. Roth, A., and Sakmann, B. (1997). Physiology and anatomy of synaptic connections between thick tufted pyramidal neurones in the developing rat neocortex. J. Physiol. 500 409-440.

Mason, A., Nicoll, A., and Stratford, K. (1991). Synaptic transmission between individual pyramidal neurons of the rat visual cortex in vitro. J. Neurosci. 11, 72-84.

Matsumura, M., Chen, D., Sawaguchi, T., Kubota, K., and Fetz, E. (1996) Synaptic interactions between primate precentral cortex neurons revealed by spike-triggered averaging of intracellular membrane potentials in vivo. $J$. Neurosci. 16, 7757-7767.

Matsuzaki, M., Ellis-Davies, G. C. R., and Kasai, H. (2008). Three-dimensional mapping of unitary synaptic connections by two-photon macro photolysis of caged glutamate. J. Neurophysiol. 99 , 1535-1544.

Miki, T., Fukui, Y., Itoh, M., Hisano, S., Xie, Q., and Takeuchi,Y.(1997).Estimation of the numerical densities of neurons and synapses in cerebral cortex. Brain Res. Protoc. 2, 9-16.

Mitchison, G., and Crick, F. (1982). Long axons within the striate cortex: their distribution, orientation, and pattern of connection. Proc. Natl. Acad. Sci. U.S.A. 79, 3661-3665.

Mountcastle, V. B. (1955). Topographic organization and modality representation in first somatic area of cat's cerebral cortex by method of single unit analysis. J. Am. Physiol. 183, 646.

Mountcastle, V. B. (1957). Modality and topographic properties of single neu- rons of cat's somatic sensory cortex. $J$ Neurophysiol. 20, 408-434.

Nawrot, M., Schnepel, P., Aertsen, A., and Boucsein, C. (2009). Precisely timed signal transmission in neocortical networks with reliable intermediate-range projections. Front. Neural Circuits 3:1 doi: 10.3389/neuro.04.001.2009

Nawrot, M. P. (2010). "Analysis and interpretation of interval and count variability in neural spike trains," in Analysis of Parallel spike Trains, eds S. Grün and S. Rotter (New York: Springer), 37-58.

Ohki, K., Chung, S., Ch'ng, Y. H., Kara P., and Reid, R. C. (2005). Functional imaging with cellular resolution reveals precise micro-architecture in visual cortex. Nature 433, 597-603.

Ohl, F. W., Scheich, H., and Freeman, W. J. (2001). Change in pattern of ongoing cortical activity with auditory category learning. Nature 412, 733-736.

Olshausen, B. A., and Field, D. J. (1996). Emergence of simple-cell receptive field properties by learning a sparse code for natural images. Nature 381, 607-609.

Olshausen, B. A., and Field, D. J. (2005). How close are we to understanding V1? Neural Comput. 17, 1665-1699.

Otazu, G. H., Tai, L., Yang, Y., and Zador, A. M. (2009). Engaging in an auditory task suppresses responses in auditory cortex. Nat. Neurosci. 12, 646-654.

Palm, G. (1982). Neural Assemblies: An Alternative Approach to Artificial Intelligence, 1st Edn. New York: Springer.

Perkel, D., and Bullock, T. (1968). Neural coding: a report based on an NRP work session. Neurosci. Res. Program Bull. 6, 219-349.

Peters, A., Kara, D. A., and Harriman, K. M. (1985). The neuronal composition of area 17 of rat visual cortex. III. Numerical considerations. J. Comp. Neurol. 238, 263-274.

Petersen, C. C. H., Grinvald, A., and Sakmann, B. (2003). Spatiotemporal dynamics of sensory responses in layer $2 / 3$ of rat barrel cortex measured in vivo by voltage-sensitive dye imaging combined with whole-cell voltage recordings and neuron reconstructions. J. Neurosci. 23, 1298-1309.

Petreanu, L., Huber, D., Sobczyk, A., and Svoboda, K. (2007). Channelrhodopsin-2-assisted circuit mapping of long-range callosal projections. Nat. Neurosci. 10, 663-668.

Poulet, J. F., and Petersen, C. C. (2008). Internal brain state regulates membrane potential synchrony in barrel cortex of behaving mice. Nature $454,881-885$.

Purves, D., Riddle, D., and LaMantia, A. (1992). Iterated patterns of brain circuitry (or how the cortex gets its spots). Trends Neurosci. 15, 362-368. 
Rickert, J., Riehle, A., Aertsen, A., Rotter, S., and Nawrot, M. P. (2009). Dynamic encoding of movement direction in motor cortical neurons. J. Neurosci. 29, 13870.

Riehle, A., Grün, S., Diesmann, M., and Aertsen, A. (1997). Spike synchronization and rate modulation differentially involved in motor cortical function. Science 278, 1950.

Rockland, K. S. (2010). Five points on columns. Front. Neuroanat. 4:22. doi: 10.3389/fnana.2010.00022

Rubio-Garrido, P., Perez-de-Manzo, F., Porrero, C., Galazo, M. J., and Clasca, F. (2009). Thalamic input to distal apical dendrites in neocortical layer 1 is massive and highly convergent. Cereb. Cortex 19, 2380-2395.

Samonds, J. M., Allison, J. D., Brown, H.A., and Bonds, A. B. (2004). Cooperative synchronized assemblies enhance orientation discrimination. Proc. Natl. Acad. Sci. U.S.A. 101, 6722.

Shepherd, G., Stepanyants, A., Bureau, I., Chklovskii, D., and Svoboda, K. (2005). Geometric and functional organization of cortical circuits. Nat. Neurosci. 8, 782-790.

Shoham, S., O'Connor, D. H., and Segev, R. (2006). How silent is the brain: is there a "dark matter" problem in neuroscience? J. Comp. Physiol. A 192, 777-784.

Simoncelli, E. P. (2003). Vision and the statistics of the visual environment. Curr. Opin. Neurobiol. 13, 144-149.

Singer, W. (1999). Neuronal synchrony: a versatile code for the definition of relations? Neuron 24, 49-65.

Skoglund, T. S., Pascher, R., and Berthold, C. (1996). Aspects of the quantitative analysis of neurons in the cerebral cortex. J. Neurosci. Methods 70, 201-210.

Song, S., Sjoström, P., Reigl, M., Nelson, S., and Chklovskii, D. (2005). Highly nonrandom features of synaptic connectivity in local cortical circuits. PLoS Biol.3, 507-519. doi: 10.1371/journal. pbio. 0030068

Staiger, J. F., Flagmeyer, I., Schubert, D., Zilles, K., Kötter, R., and Luhmann, H. J. (2004). Functional diversity of layer IV spiny neurons in rat somatosensory cortex: quantitative morphology of electrophysiologically characterized and biocytin labeled cells. Cereb. Cortex 14, 690-701.

Stepanyants, A., Hirsch, J., Martinez, L., Kisvárday, Z., Ferecskó, A., and Chklovskii, D. (2008). Local potential connectivity in cat primary visual cortex. Cereb. Cortex 18, 13-28.

Stepanyants, A., Martinez, L. M., Ferecskó, A. S., and Kisvárday, Z. F. (2009). The fractions of short- and long-range connections in the visual cortex. Proc. Natl. Acad. Sci. U.S.A. 106,3555-3560.

Super, H., Van Der Togt, C., Spekreijse, H., and Lamme, V.A. (2003). Internal state of monkey primary visual cortex (V1) predicts figure-ground perception. $J$. Neurosci. 23, 3407.

Thomson, A., and Bannister, A. (2003). Interlaminar connections in the neocortex. Cereb. Cortex 13, 5-14.

Thomson, A., and Lamy, C. (2007). Functional maps of neocortical local circuitry. Front. Neurosci. 1, 19-42.

Thomson, A., West, D., Wang, Y., and Bannister, A. (2002). Synaptic connections and small circuits involving excitatory and inhibitory neurons in layers $2-5$ of adult rat and cat neocortex: triple intracellular recordings and biocytin labelling in vitro. Cereb. Cortex 12, 936-953.

Tiesinga, P., Fellous, J., and Sejnowski, T. (2008). Regulation of spike timing in visual cortical circuits. Nat. Rev. Neurosci. 9, 97-109.

Tsodyks, M. (1999). Linking spontaneous activity of single cortical neurons and the underlying functional architecture. Science 286, 1943-1946.

Tucker, T. R., and Katz, L. C. (2003). Spatiotemporal patterns of excitation and inhibition evoked by the horizontal network in layer $2 / 3$ of ferret visual cortex. J. Neurophysiol. 89, 488-500.

Vaadia, E., Haalman, I., Abeles, M. Bergman, H., Prut, Y., Slovin, H., and Aertsen, A. (1995). Dynamics of neuronal interactions in monkey cortex in relation to behavioural events. Nature 373, 515-518.

Van Hooser, S. D. (2007). Similarity and diversity in visual cortex: is there a unifying theory of cortical computation? Neuroscientist 13, 639-656.

Van Hooser, S. D., Heimel, J. A., Chung, S., and Nelson, S. B. (2006). Lack of patchy horizontal connectivity in primary visual cortex of a mammal without orientation maps. J. Neurosci. 26, 7680-7692.

van Rullen, R., and Thorpe, S. J. (2002) Surfing a spike wave down the ventral stream. Vision Res. 42, 2593-2615.

Vinje, W. E., and Gallant, J. L. (2000). Sparse coding and decorrelation in primary visual cortex during natural vision. Science 287, 1273-1276.

Voges, N., Guijarro, C., Aertsen, A., and Rotter, S. (2010a). Models of cortical networks with long-range patchy projections. J. Comput. Neurosci. 28 , 137-154.

Voges, N., Schüz, A., Aertsen, A., and Rotter, S. (2010b). A modeler's view on the spatial structure of intrinsic horizontal connectivity in the neocortex. Prog. Neurobiol. 92, 277-292.

Weliky, M., and Katz, L. C. (1994). Functional mapping of horizontal connections in developing ferret visual cortex: experiments and modeling. $J$. Neurosci. 14, 7291-7305.

Wolfe, J., Houweling, A. R., and Brecht, M. (2010). Sparse and powerful corti- cal spikes. Curr. Opin. Neurobiol. 20 306-312.

Yang, Y., DeWeese, M. R., Otazu, G.H., and Zador,A.M. (2008). Millisecond-scale differences in neural activity in auditory cortex can drive decisions. Nat. Neurosci. 11, 1262-1263.

Yen, S., Baker, J., and Gray, C. M. (2006). Heterogeneity in the responses of adjacent neurons to natural stimuli in cat striate cortex. J. Neurophysiol. 97, 1326-1341.

Yoshimura, Y., Sato, H., Imamura, K. and Watanabe, Y. (2000). Properties of horizontal and vertical inputs to pyramidal cells in the superficial layers of the cat visual cortex. J. Neurosci. 20, 1931-1940.

Young, M. P., and Yamane, S. (1992). Sparse population coding of faces in the inferotemporal cortex. Science 256,1327

Conflict of Interest Statement: The authors declare that the research was conducted in the absence of any commercial or financial relationships that could be construed as a potential conflict of interest.

Received: 23 November 2010; paper pending published: 10 January 2011; accepted: 28 February 2011; published online: 01 April 2011.

Citation: Boucsein C, Nawrot MP, Schnepel $P$ and Aertsen A (2011) Beyond the cortical column: abundance and physiology of horizontal connections imply a strong role for inputs from the surround. Front. Neurosci. 5:32. doi: 10.3389/fnins.2011.00032 Copyright (C) 2011 Boucsein, Nawrot Schnepel and Aertsen. This is an openaccess article subject to an exclusive license agreement between the authors and Frontiers Media SA, which permits unrestricted use, distribution, and reproduction in any medium, provided the original authors and source are credited. 